\title{
Article \\ Sleep Instability Correlates with Attentional Impairment in Boys with Attention Deficit Hyperactivity Disorder
}

\author{
Katia Gagnon ${ }^{1,2,+}$, Mélanie Labrosse ${ }^{1,+}$, Marc-André Gingras ${ }^{1}$ and Roger Godbout ${ }^{1,2, *(D)}$ \\ 1 Sleep Laboratory and Clinic, Hôpital en Santé mentale Rivière-des-Prairies, Montréal, QC H1E 1A4, Canada; \\ katia.gagnon@umontreal.ca (K.G.); melanie.labrosse@umontreal.ca (M.L.); \\ magingras.neuropsychologue@gmail.com (M.-A.G.) \\ 2 Department of Psychiatry, Université de Montréal, Montréal, QC H3T 1J4, Canada \\ * Correspondence: roger.godbout@umontreal.ca \\ + These authors contributed equally to this work.
}

Citation: Gagnon, K.; Labrosse, M.; Gingras, M.-A.; Godbout, R. Sleep Instability Correlates with Attentional Impairment in Boys with Attention Deficit Hyperactivity Disorder. Brain Sci. 2021, 11, 1425. https://doi.org/ $10.3390 /$ brainsci11111425

Academic Editor: Alexander

Prehn-Kristensen

Received: 4 September 2021

Accepted: 22 October 2021

Published: 27 October 2021

Publisher's Note: MDPI stays neutral with regard to jurisdictional claims in published maps and institutional affiliations.

Copyright: (c) 2021 by the authors. Licensee MDPI, Basel, Switzerland. This article is an open access article distributed under the terms and conditions of the Creative Commons Attribution (CC BY) license (https:// creativecommons.org/licenses/by/ $4.0 /)$.

\begin{abstract}
Theoretical models of sleep and attention deficit hyperactivity disorder (ADHD) suggest that symptoms of ADHD are associated with daytime sleepiness, but it has received little support. The present study aimed at testing an alternative model involving the association of attentional instability with sleep instability, i.e., sleep stage transitions and arousals. Twelve ADHD and 15 healthy control (HC) boys aged between 8 and 12 years old underwent polysomnography recording and attentional testing. The microarousal index, the number of awakenings, and the number of stage shifts between stages 1, 2, 3, 4 and REM sleep throughout the night were computed as sleep stability parameters. Attentional functioning was assessed using the Continuous Performance Test-II. We found significantly higher sleep instability in ADHD compared to HC. Sleep arousals and stage transitions (micro arousal index, stage 4/3 and 2/4 transitions) in ADHD significantly correlated with lower attentional scores. No association whatsoever was found between sleep instability and attentional functioning in HC. The results show that sleep instability is associated with lower attentional performance in boys with ADHD, but not in HC. This could be compatible with a model according to which attention and sleep stability share a common neural substrate in ADHD.
\end{abstract}

Keywords: attention deficit and hyperactivity disorder; polysomnography; sleep instability; stage shifting; cognition; attention functioning

\section{Introduction}

Attention deficit hyperactivity disorder (ADHD), one of the most prevalent neurocognitive disorders in childhood, is characterized by impaired attention, impulsivity, and excessive motor activity, which reduces the quality of social, academic, or occupational functioning [1]. Although ADHD is associated with structural and functional changes in the brain, the neural mechanisms implicated in inattention and impulsivity are still unclear $[2,3]$. Several theoretical models of ADHD have been put forward, but they have often ignored sleep issues that occur in almost half of children with ADHD, based mostly on parental reports $[4,5]$, while sleep macrostructure as measured with polysomnography appeared to be less sensitive [4,6,7].

Over the past years, several models linking ADHD signs and symptoms to sleep have been proposed. Since neurochemical and anatomical structures that modulate attention are also involved in arousal and sleep, a consensus working group of researchers suggested that sleep and attention dysfunction in children with ADHD could be an expression of the alteration of the neural circuitry that regulates both sleep/wake and attention [6]. Acting as a common pathophysiological pathway, defects in neuronal networks in ADHD could thus lead to both sleep instability, defined here as arousals/microarousals and sleep stage shifts, as well as impaired cognitive performance. 
Very few studies have investigated sleep stability in ADHD, yielding mixed results, possibly because varied methods were used [7-9]. Moreover, these studies have not tested the link between sleep instability and cognitive functioning in ADHD. Our study aimed at comparing sleep stability of children with ADHD to healthy control (HC) children using polysomnography, paired with cognitive performance testing. We hypothesized that: (a) sleep macrostructure would not be different between ADHD children and HC children;

(b) ADHD children would display more sleep instability compared to HC children; and (c) sleep instability would be associated with a lower performance on cognitive measures of attention in children with ADHD.

\section{Materials and Methods}

\subsection{Participants}

Twelve right-handed boys with ADHD, aged between 8 and 12 years old, were recruited through a specialized clinic for ADHD at the Hôpital en santé mentale Rivièredes-Prairies, (Montréal, QC, Canada). Inclusion criteria were: (1) a diagnosis of ADHD made by a psychiatrist; (2) no comorbid psychiatric, neurological, or medical disorders, including sleep disorders, as determined by a sleep specialist on site; and (3) a full-scale intelligence quotient (IQ) above 80, as measured by the Kaufman Brief Intelligence Test [10]. DSM-IV criteria were used to diagnose ADHD and other comorbid psychiatric disorders. Children with ADHD all met criteria for ADHD combined type [11]. All ADHD children were treated with the stimulant medication methylphenidate, except for two who were treated with atomoxetine, a non-stimulant medication. The ADHD group was compared to 15 right-handed (HC) boys, aged between 8 and 12 years old, recruited through public announcements. Exclusion criteria for HC boys were: (1) a personal history of psychiatric, neurological, or other medical conditions, including sleep disorders; (2) medication use that can affect the central nervous system; and (3) a full-scale IQ below 80 as measured by the Kaufman Brief Intelligence Test [10]. The ADHD and HC children were recruited and studied all year round, alternating between ADHD and HC participants most of the time in order to avoid a sequence effect.

The parents of all children completed the Child Behavior Checklist/4-18 (CBCL) [12]. Raw scores were converted into age-standardized scores. The total scores, the attention scale scores, and the anxiety/depression scores were used to compare ADHD and HC groups.

\subsection{Procedure}

Under the supervision of their parents, participants were asked to keep a regular sleep-wake schedule and complete a sleep diary for 14 days before coming to the laboratory. Parents were asked to complete a sleep questionnaire (Children's Sleep Habits Questionnaire: CSHQ) [13] and an ADHD symptom severity questionnaire (Child Behavior Checklist/4-18) [12]. Napping, drinking caffeine beverages, and eating chocolate was not permitted on the day prior the recordings; none of the children were usual nappers. ADHD participants were withdrawn from psychostimulant medication (methylphenidate) for at least $48 \mathrm{~h}$ before sleep recording until the end of the study. Non-stimulant medication (atomoxetine, in two children) was maintained during the protocol. Participants slept in the laboratory for two consecutive nights, and their parents were sleeping in an adjoining bedroom. The first laboratory night served to screen sleep disorders, and to allow adaptation to the experimental environment. Polysomnographic data presented are from the second night. Cognitive testing was carried out between 8:00 a.m. and noon after night 2, in a quiet testing room, by a well-trained and experienced psychotechnician.

The protocol was approved by the ethic committee of the Hôpital en santé mentale Rivière-des-Prairies (reference approval number 03-07). Informed consent was obtained from both children and parents. All participants received a financial compensation for their involvement in this research. 


\subsection{Polysomnographic Recordings}

Sleep was recorded and scored according to standard methods, using 20-s epochs [14,15]. Electro-oculogram (EOG) electrodes were applied over each outer canthus, and surface electromyogram (EMG) electrodes applied over the submental muscles. Electroencephalographic (EEG) electrodes were positioned according to the international 10-20 system for frontal (F3, F4), central $(\mathrm{C} 3, \mathrm{C} 4)$, and occipital $(\mathrm{O} 1, \mathrm{O} 2)$ recording sites. EEG leads were referenced to linked earlobes $(\mathrm{A} 1+\mathrm{A} 2)$, with a serial $10 \mathrm{~K} \Omega$ resistor for impedance equilibrium purposes $[16,17]$. Periodic leg movements in sleep (PLMS) were monitored with bilateral anterior tibialis muscle surface EMG. PLMS scoring criteria were as follows: at least 4 anterior tibialis EMG bursts separated by at least $5 \mathrm{~s}$, and at most by $90 \mathrm{~s}$ intervals. Respiratory flow and effort were monitored using oronasal cannula and thoracoabdominal strain gauges, respectively. Arterial oxygen saturation $(\mathrm{SaO} 2)$ was measured with an infrared oximetry sensor to the index finger (Datex Ohmeda 3900 Pulse Oxymeter, Datex-Ohmeda, Louisville, CO, USA). The identification criteria for sleep apnea were those of the American Academy of Sleep Medicine [18].

A Grass Neurodata Model 12 Acquisition system was used for recording, and signals were digitized using Harmonie 5.0 Software (Stellate, Montreal, QC, Canada). Filter settings and amplification factors for EEG were: $1 / 2$ amplitude high pass $=0.3 \mathrm{~Hz}, 1 / 2$ amplitude low pass $=30 \mathrm{~Hz}$, amplification $\times 1000=20$; EOG: $1 / 2$ amplitude high pass $=0.1 \mathrm{~Hz}$, $1 / 2$ amplitude low pass $=30 \mathrm{~Hz}$, amplification $\times 1000=20$; EMG: $1 / 2$ amplitude high pass $=10.0 \mathrm{~Hz}, 1 / 2$ amplitude low pass $=100 \mathrm{~Hz}$, amplification $\times 300=20$. Signals were sampled at $256 \mathrm{~Hz}$. Records were stored for offline visual analysis on a computer screen.

\subsection{Sleep Architecture}

Sleep onset was defined as 10 consecutive minutes of stage 1, or the first epoch of any other sleep stage. Sleep latency to sleep stages was the interval between sleep onset and the first epoch of that stage. REM latency was the interval between sleep latency and the first REM sleep epoch. The sleep period was defined as the time elapsed from sleep onset to sleep offset (last awakening). Total sleep time was the total number of minutes spent during the sleep period. Sleep efficiency was computed by the following formula: total sleep stages duration/sleep period $\times 100$; a REM sleep period was defined as a succession of REM sleep epochs not interrupted for more than $15 \mathrm{~min}$. REM sleep efficiency was calculated as: total duration of REM sleep/total duration of REM periods $\times 100$.

\subsection{Sleep Stability Parameters}

Sleep stability was assessed with three measures computed through the sleep period: stage shifts, awakenings, and microarousals. Stage shifts were identified as transitions from a sleep stage to wake or another sleep stage. Awakenings were defined as epochs scored as wake stage. Microarousals were defined as awakenings shorter than $10 \mathrm{~s}$. The microarousal index corresponds to the number of events per hour of sleep.

\subsection{Cognitive Testing}

Attentional functioning was tested using the Continuous performance Test- Second edition (CPT-II), a computer-based program that measures attention problems in individuals of 6 years of age and older [19]. Letters were presented on the center of the screen, and children were required to press the spacebar as quickly as possible in response to any letters other than " $X$ ", and not to respond when the " $X$ " letter was presented. Letters were presented on the screen for $250 \mathrm{~ms}$ at varying time intervals of one-, two-, and four-second intervals between stimuli. There was a two-minute practice test, and then the main test was administered for an approximate duration of $14 \mathrm{~min}$. The assessment was segmented into six blocks, each with three sub-blocks. A total of 360 stimuli, including 36 " $\mathrm{X}$ ", appeared over the duration of the test. Thirteen different metrics were calculated by the program, and converted into standard scores. Mean reaction time, omission errors (not responding to a letter other than " $\mathrm{X}$ "), and commission errors (responding to an " $\mathrm{X}$ ") were computed as 
measures of attention functioning. Reliability of these measures is estimated to be between 0.83 to 0.95 [19]. Standard scores were used for group comparison and correlations. Higher scores are associated with lower performance.

\subsection{Questionnaires}

\subsubsection{Child Behavior Checklist/4-18 (CBCL)}

The Child Behavior Checklist/4-18 is a parent-completed questionnaire that measures children's adaptive behavior using a three-level scale: "true or often true", "somewhat or sometimes true", and "not true" [12]. The scale yields eight behavioral constructs, including anxious/depressed and attention problems. The CBCL generates a total score that can be converted into standardized scores. Higher scores are associated with more behavioral issues, and a $\mathrm{T}$ score above 70 is in the clinical range. CBCL is a valid and clinically useful instrument for the evaluation of children referred for ADHD, and the attention problem subscale is a good predictor of ADHD diagnosis [20-23].

\subsubsection{Children's Sleep Habits Questionnaire (CSHQ)}

The Children's Sleep Habits Questionnaire (CSHQ) is a retrospective, 45 -items questionnaire that was developed to examine sleep behavior in children [13]. Parents were asked to rate their children sleep behaviors over a typical week. The CSHQ uses three level scales: "usually" (5 to 7 times per week), "sometimes" (2 to 4 times per week), and "rarely" (0 to 1 time per week). The questionnaire is segmented into subscales, including daytime sleepiness. A higher score indicates more disrupted sleep. Test-retest reliability show a Cronbach's alpha of 0.78 for global scale, and a range between 0.56 and 0.93 for subscales [24]. A score of 41 or above is in the clinical range. The total score showed good validity to differentiate controls from a sleep-disorder group (sensitivity 0.80 and specificity of 0.72 ; ROC curve $=0.41$ ) [13].

\subsection{Statistical Analysis}

Statistical analyses were performed with SPSS 25.0 (SPSS Science, Chicago, IL, USA), and statistical significance was set at $p<0.05$. Distribution normality was investigated, and appropriate transformations were applied to non-normally distributed variables. Power analysis, based on the literature on sleep instability in ADHD children, shows that a sample of 26 participants can provide large effect sizes $(\alpha=0.05 ; 1-\beta=0.80)$.

Because there are no clinical cutoff scores for the CSHQ sleepiness subscale, we transformed the individuals' absolute scores into Z scores, using the mean and standard deviations of the 381 healthy control children in Owens et al., 2000, and we used two standard deviations over the mean as a cutoff score [13].

Student $t$-tests were used to test group differences (ADHD vs. HC) on demographic, sleep, and cognitive variables. Levene's tests were applied for homogeneity of variance. For each group, we used Pearson's correlations between sleep stability variables that were found to be significantly different between groups, and cognitive measures of attention on CPT-II (reaction times, omission errors, commission errors) to test the relation between sleep stability and cognitive functioning. Pearson's correlations were also used to measure the association between sleep stability variables and CBCL attention scores.

\section{Results}

\subsection{Clinical Characteristics and Sleep Macroarchitecture}

Table 1 shows that groups were not different on age, body mass index, and IQ. Compared to HC, the ADHD group displayed significantly higher scores on the CBCL total and attention scores, but no significant differences were found on the anxiety/depression scores. No significant differences were found on the CPT-II. The total score on the CHSQ was higher in the ADHD group compared to $\mathrm{HC}$, but no differences were found on the sleepiness subscale. Table 2 shows that ADHD and HC groups were not different on sleep macroarchitecture variables. Levene's tests were not significant. 
Table 1. Clinical characteristics.

\begin{tabular}{|c|c|c|c|}
\hline & $\mathrm{HC}$ & ADHD & $\begin{array}{l}\text { Student-t } \\
p \text {-Values }\end{array}$ \\
\hline Participants (n) & 15 & 12 & \\
\hline Age (years) & $10.7 \pm 1.6$ & $11.0 \pm 1.2$ & 0.620 \\
\hline Body mass index & $18.9 \pm 5.6$ & $16.7 \pm 2.5$ & 0.251 \\
\hline Intellectual Quotient & $111.5 \pm 10.6$ & $105.5 \pm 15.0$ & 0.233 \\
\hline \multicolumn{4}{|l|}{ CBCL } \\
\hline Total score & $20.1 \pm 15.3$ & $50.3 \pm 27.7$ & $0.002^{* *}$ \\
\hline $\begin{array}{c}\text { Anxiety/Depression } \\
\text { score }\end{array}$ & $3.0 \pm 3.4$ & $7.2 \pm 6.3$ & 0.065 \\
\hline Attention score & $2.0 \pm 1.8$ & $9.9 \pm 4.2$ & $0.000^{* *}$ \\
\hline \multicolumn{4}{|l|}{ CPT-II } \\
\hline Omissions & $47.3 \pm 6.4$ & $67.4 \pm 50.3$ & 0.183 \\
\hline Commissions & $49.7 \pm 12.5$ & $57.8 \pm 5.2$ & 0.061 \\
\hline Hit Reaction time & $47.9 \pm 13.0$ & $51.8 \pm 25.7$ & 0.810 \\
\hline \multicolumn{4}{|l|}{ CSHQ } \\
\hline Total score & $37.1 \pm 0.8$ & $43.1 \pm 0.9$ & $0.002^{* *}$ \\
\hline Daytime sleepiness & $10.9 \pm 2.2$ & $12.1 \pm 2.6$ & 0.307 \\
\hline $\begin{array}{l}\text { Number of children with } \\
\text { significant sleepiness }\end{array}$ & 0 & 1 & n.a. \\
\hline
\end{tabular}

Table 2. Sleep macroarchitecture.

\begin{tabular}{cccc}
\hline & $\begin{array}{c}\text { HC } \\
(\boldsymbol{n}=\mathbf{1 5})\end{array}$ & $\begin{array}{c}\text { ADHD } \\
(\boldsymbol{n}=\mathbf{1 2})\end{array}$ & $\begin{array}{c}\text { Student-t } \\
\boldsymbol{p} \text {-Values }\end{array}$ \\
\hline Sleep Latency (min) & $15.8 \pm 15.4$ & $13.1 \pm 11.9$ & 0.517 \\
TST (min) & $564.5 \pm 77.2$ & $541.0 \pm 60.8$ & 0.398 \\
Sleep Efficiency (\%) & $97.4 \pm 2.5$ & $97.4 \pm 2.0$ & 0.718 \\
Stage 1 (\%) & $3.8 \pm 1.2$ & $3.2 \pm 1.5$ & 0.241 \\
Stage 2 (\%) & $50.8 \pm 4.3$ & $52.1 \pm 5.3$ & 0.502 \\
Stage 3 (\%) & $8.8 \pm 2.9$ & $9.7 \pm 3.0$ & 0.422 \\
Stage 4 (\%) & $16.0 \pm 4.1$ & $13.7 \pm 4.6$ & 0.091 \\
REM sleep (\%) & $20.5 \pm 3.9$ & $21.9 \pm 3.9$ & 0.364 \\
REM sleep latency (min) & $101.5 \pm 43.1$ & $81.1 \pm 52.3$ & 0.277 \\
REM sleep duration & $132.8 \pm 30.2$ & $135.4 \pm 30.2$ & 0.820 \\
REM sleep efficiency (\%) & $87.7 \pm 6.8$ & $88.0 \pm 4.9$ & 0.909 \\
Mean SpO $2 \%$ (\%) & $99.3 \pm 0.5$ & $99.1 \pm 0.6$ & 0.554 \\
Minimum SpO $(\%)$ & $81.6 \pm 9.3$ & $85.0 \pm 5.1$ & 0.309 \\
Time with SpO 2 ( $90 \%$ (min) & $0.96 \pm 1.2$ & $0.51 \pm 0.74$ & 0.119 \\
Apnea-Hypopnea Index (no/h) & $2.8 \pm 1.7$ & $3.1 \pm 1.4$ & 0.584 \\
Periodic leg movement index & $8.7 \pm 5.0$ & $10.4 \pm 8.0$ & 0.501 \\
(no/h) & & & \\
\hline
\end{tabular}

Results are presented as mean \pm standard deviation. ADHD: attention deficit hyperactivity disorder; HC: healthy control; REM sleep: rapid eye movement sleep; TST: total sleep time; min: minutes; no/h: number per hour of sleep.

\subsection{Sleep Stability}

Compared to HC, the ADHD group showed a higher microarousal index during Stage 1, as well as more transitions from Stage 2 to REM sleep, and from REM sleep to Stage 2; transitions from Stage 4 to Stage 3 were also higher in the ADHD group compared to HC. The HC group displayed a higher number of transitions from Stage 2 to Stage 4 , 
and from Stage 4 to Stage 2 compared to the ADHD group (Table 3). Levene's tests were not significant.

Table 3. Sleep stability.

\begin{tabular}{|c|c|c|c|}
\hline & $\begin{array}{c}\text { HC } \\
(n=15)\end{array}$ & $\begin{array}{l}\text { ADHD } \\
(n=12)\end{array}$ & $\begin{array}{l}\text { Student-t } \\
p \text {-Values }\end{array}$ \\
\hline \multicolumn{4}{|l|}{ Awakenings } \\
\hline Number & $15.7 \pm 7.0$ & $15.4 \pm 9.9$ & 0.939 \\
\hline Minutes & $14.3 \pm 12.3$ & $14.6 \pm 12.8$ & 0.884 \\
\hline \multicolumn{4}{|l|}{ Microarousal index (no/h) } \\
\hline Total & $4.6 \pm 2.0$ & $5.3 \pm 2.0$ & 0.333 \\
\hline Stage 1 & $12.9 \pm 8.0$ & $25.4 \pm 19.5$ & $0.034 *$ \\
\hline Stage 2 & $5.9 \pm 2.9$ & $6.5 \pm 2.6$ & 0.594 \\
\hline Stage 3 & $6.9 \pm 4.3$ & $4.8 \pm 3.1$ & 0.159 \\
\hline Stage 4 & $1.5 \pm 1.5$ & $1.8 \pm 2.0$ & 0.668 \\
\hline REM sleep & $1.2 \pm 1.5$ & $2.1 \pm 1.9$ & 0.191 \\
\hline \multicolumn{4}{|l|}{$\begin{array}{l}\text { Transitions towards } \\
\text { deeper sleep stages }\end{array}$} \\
\hline Wake to Stage 1 & $16.7 \pm 6.0$ & $16.5 \pm 9.4$ & 0.938 \\
\hline Wake to Stage 2 & $0.7 \pm 1.5$ & $0.8 \pm 1.2$ & 0.665 \\
\hline Stage 1 to Stage 2 & $15.2 \pm 6.7$ & $14.1 \pm 5.9$ & 0.653 \\
\hline Stage 1 to Stage 3 & $0.1 \pm 0.4$ & $0.0 \pm 0.0$ & 0.203 \\
\hline Stage 2 to Stage 3 & $52.7 \pm 31.9$ & $43.7 \pm 13.3$ & 0.599 \\
\hline Stage 2 to Stage 4 & $1.1 \pm 1.1$ & $0.4 \pm 0.5$ & $0.04 *$ \\
\hline Stage 3 to Stage 4 & $20.5 \pm 7.3$ & $29.3 \pm 13.2$ & 0.064 \\
\hline \multicolumn{4}{|l|}{$\begin{array}{c}\text { Transitions to lighter } \\
\text { sleep stages }\end{array}$} \\
\hline Stage 1 to Wake & $5.9 \pm 3.4$ & $6.3 \pm 4.5$ & 0.937 \\
\hline Stage 2 to Wake & $8.7 \pm 5.5$ & $8.0 \pm 5.2$ & 0.683 \\
\hline Stage 2 to Stage 1 & $2.9 \pm 2.3$ & $2.9 \pm 2.6$ & 0.986 \\
\hline Stage 3 to Awake & $0.5 \pm 0.6$ & $0.2 \pm 0.4$ & 0.179 \\
\hline Stage 3 to Stage 2 & $51.1 \pm 31.5$ & $42.8 \pm 13.4$ & 0.652 \\
\hline Stage 4 to Stage 2 & $2.1 \pm 1.8$ & $0.9 \pm 0.8$ & $0.046^{*}$ \\
\hline Stage 4 to Stage 3 & $19.6 \pm 6.7$ & $28.7 \pm 13.2$ & $0.048 *$ \\
\hline \multicolumn{4}{|l|}{ REM Sleep Transitions } \\
\hline Stage 1 to REM sleep & $11.4 \pm 6.5$ & $9.0 \pm 4.4$ & 0.268 \\
\hline Stage 2 to REM sleep & $9.9 \pm 2.7$ & $13.1 \pm 5.0$ & 0.044 * \\
\hline Stage 3 to REM sleep & $0.3 \pm 0.6$ & $0.3 \pm 0.5$ & 0.699 \\
\hline Stage 4 to REM sleep & $0.0 \pm 0.0$ & $0.01 \pm 0.3$ & 0.272 \\
\hline REM sleep to Wake & $2.4 \pm 1.8$ & $2.9 \pm 3.1$ & 0.591 \\
\hline REM sleep to Stage 1 & $12.9 \pm 6.3$ & $9.8 \pm 5.4$ & 0.191 \\
\hline REM sleep to Stage 2 & $6.3 \pm 2.8$ & $9.5 \pm 5.0$ & $0.047^{*}$ \\
\hline REM sleep to Stage 3 & $0.0 \pm 0.0$ & $0.1 \pm 0.3$ & 0.272 \\
\hline
\end{tabular}

Results are presented as mean \pm standard deviation. ADHD: attention deficit hyperactivity disorder; HC: healthy control; no/h: number per hour of sleep; REM: rapid eye movement. * $p<0.05$.

\subsection{Association between Sleep Stability and Attention}

In the ADHD group, higher omission scores $(r=0.42 ; p=0.048)$ and commission scores $(r=0.82 ; p=0.002)$ were significantly correlated with higher Stage 1 microarousal index values (Figure 1A,B) while higher omission scores were associated with more transitions from Stage 4 to Stage $3(r=0.46 ; p=0.03)$ (Figure 1C). There were no significant correlations CPT-II scores and REM sleep stability variables. No significant correlations between sleep stability variables and CPT-II measures whatsoever were found in the HC group. No significant correlations were found between CBCL attention scores and sleep stability in either of the two groups. 


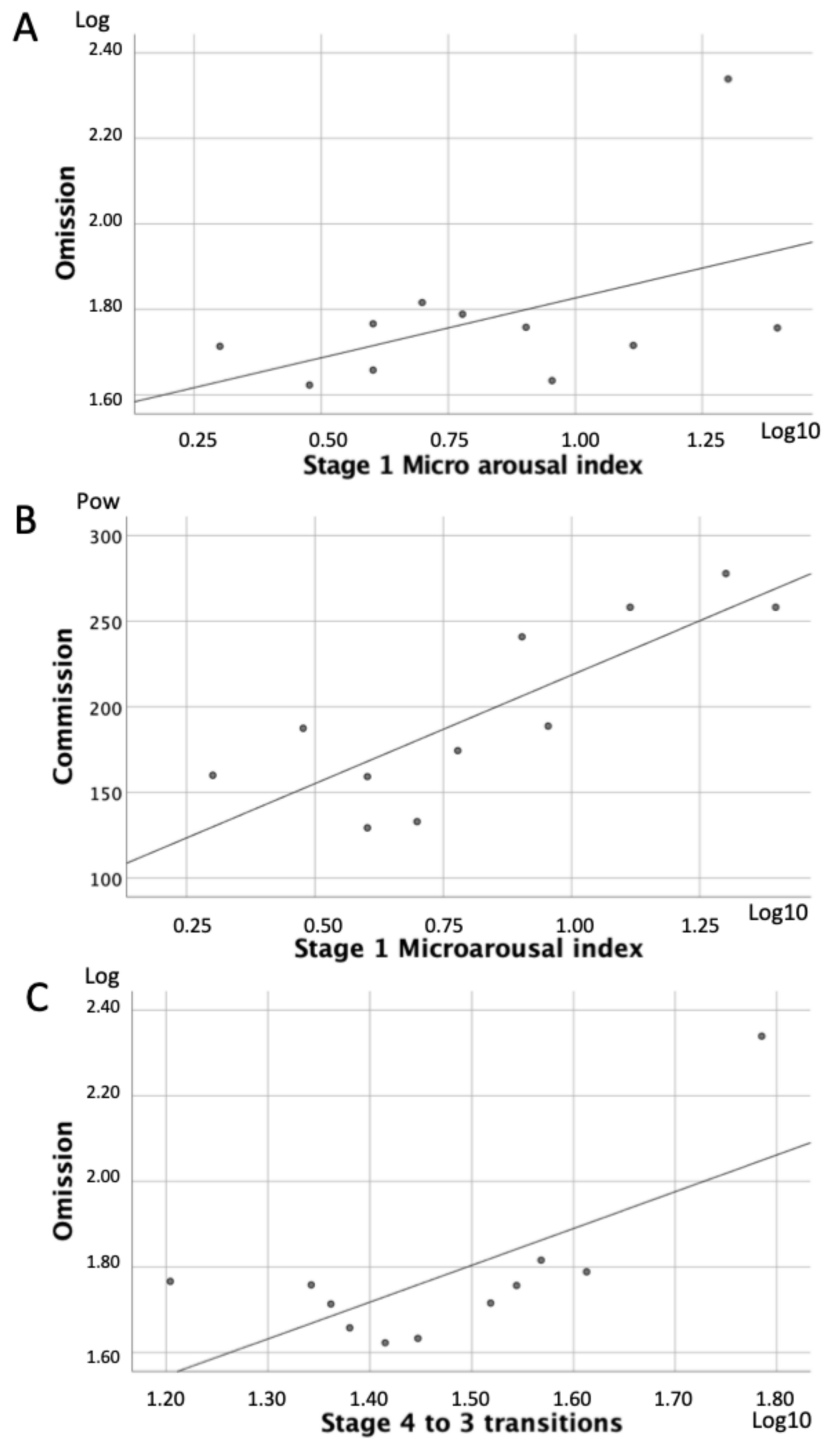

Figure 1. Correlations between sleep stability and attention in children with ADHD. $(\mathbf{A}, \mathbf{B})$ illustrate significant correlations between Stage 1 Microarousal index and attention scores of omission and commission, respectively. (C) significant association between omission scores and transitions between sleep stages 4 to 3 .

\section{Discussion}

As hypothesized, the ADHD group showed a higher number of transitions from deeper to lighter stages of sleep, compared to the HC group. They also showed a higher number of bidirectional transitions between REM sleep and Stage 2. Interestingly, only transitions to lighter non-REM sleep stages positively correlated with lower scores on objective attentional measures in the ADHD group. The HC group displayed significantly more bidirectional transitions between sleep Stages 2 and 4, but these measures did not correlate with attentional performance. Taken together, these results suggest that sleep instability towards lighter sleep stages of non-REM sleep and lower attentional performance share a common pathophysiological pathway in children with ADHD that is not active in HC.

\subsection{How the Present Results Fit into Existing Models of Sleep Instability in ADHD?}

There are three major models of sleep instability in ADHD. The first model suggests that ADHD could be associated with an hypoarousal state resembling narcolepsy [25]. This model involves an increase in daytime sleepiness, and a decrease in the markers of sleep 
stability, as measured by electroencephalography (EEG) cycling alternating patterns [7,25]. Two studies found a lower rate of cycling alternating patterns in ADHD children [7,8], while a third one did not [9]. More importantly, one of these studies did not assess sleepiness [9], while the two others, either using their own children-adapted version of the Epworth Sleepiness Scale or the Sleep Disturbance Scale for Children [26], found sleepiness in only two of 20 [7] and three of 28 [8] ADHD children, respectively. The present study found more sleep instability in boys with ADHD compared to controls, but we did not find between-group differences on either subjective (CSHQ) or objective (CPT-II) measures of sleepiness. Moreover, only one ADHD child in the present study had a score on the CHSQ's sleepiness subscale that exceeded 2 standard deviations over the mean of the 381 healthy control children, published in Owens et al., 2000 [13]. These results are not compatible with this first model.

A second model was recently proposed by Andrillion et al., 2019, according to which sleep and wakefulness are considered as a continuum, rather than mutually exclusive states [3]. Partially supporting this idea, studies using topographical analyses of the EEG during non-REM have documented local changes in sleep depth across the scalp during non-REM sleep in healthy adults without sleep disturbances $[27,28]$. Other studies have reported local sleep-like non-REM sleep slow waves occurring at the level of single-neuron activity during wakefulness and REM sleep [29-34]. Local sleep occurring during wakefulness has been associated with attentional lapses, slower reaction times, and increased error rates [28-30,32,34]. According to this model, the alteration of the neural circuits regulating attention and sleep/wake in ADHD could lead to a higher number of awakenings during sleep, or sleep instability, which could negatively impact daytime cognitive performance due to of daytime sleepiness [3]. Although we found a significant correlation between sleep instability and attentional functioning, the lack of sleepiness in our ADHD group may not support this model.

A third model was proposed by a multidisciplinary workgroup of pediatric sleep researchers, putting forward the idea that the neural circuitry involved in sleep/wake regulation also controls attention. Our results match well with this theoretical framework, as sleep instability, as measured by more microarousals and more transitions to lighter sleep stages, was associated with lower attentional functioning, without significant daytime sleepiness. Moreover, a study by Miano et al. also found a higher number of transitions between unspecified sleep stages in ADHD children compared to controls and, as in the present study, with only 2 of 20 ADHD children presenting symptoms of daytime sleepiness [7]. The association between sleep instability in ADHD and attentional measures, however, was not tested. Although the authors did not report on the direction in which sleep stage transitions occurred, these results suggest that neurodevelopmental defects associated with ADHD could have a negative impact on both sleep stability and attention functioning, but not on daytime sleepiness. The next section will discuss the potential neural structures and neurotransmitters that could be involved in both sleep instability and attentional performance in ADHD.

\subsection{What Are the Potential Brain Networks Involved in Both Attention Functioning and Sleep Instability in $A D H D$ ?}

It is known that individuals with ADHD exhibit alertness/attention instability [35]. Methylphenidate, a psychostimulant acting on the dopaminergic and noradrenergic systems, is commonly used to treat ADHD by improving attention stability [36,37]. The main neuroanatomical structure providing noradrenergic release throughout the brain is the locus coeruleus [38]. In addition to contributing to cognitive functions regulations, such as attention, vigilance, and memory, the locus coeruleus is also involved in sleep regulation, including sleep stage stability [39]. Over the following sections we will look at each significant sleep transitions in ADHD, and evaluate how the previous structures and neurotransmitters are potentially participating to sleep instability. 


\subsubsection{Sleep Stage 1 to Micro-Arousal Oscillations}

Microarousals are generated, at least partially, by the same structures involved in maintaining arousal [40]. The cerebral cortex, basal forebrain, and hypothalamus are diffusely innervated by monoaminergic groups of cells that drive arousal through the secretion of norepinephrine, serotonin, dopamine, and histamine [41,42]. The locus coeruleus, which is the largest group of noradrenergic neurons, plays a major key role in wakefulness through multiple excitatory projections to wakefulness-promoting nucleus, and inhibitory projections to sleep-promoting nucleus $[41,43,44]$. Thus, a neurodevelopmental impairment of the noradrenergic system could reduce alertness during the daytime, and increase sleep awakenings at night [43].

\subsubsection{Oscillations between Sleep Stages 3 and 4}

The noradrenergic system, including the locus coeruleus, modulates cortical activity during non-REM sleep. Using a coupling method between EEG and functional magnetic resonance imaging, Dang-Vu et al., 2008 found a temporal relationship between locus coeruleus activity and slow EEG oscillations [44]. Eschenko et al., 2011 also showed that locus coeruleus firing was associated with the rising phase of the EEG slow waves in rodents [45]. The locus coeruleus is thus involved in neuromodulatory processes, by increasing cortical excitability [45]. As mentioned earlier, noradrenergic neurotransmission appears to be unstable in children with ADHD. Thus, the capacity to increase cortical excitability, or to trigger firing in the locus coeruleus in order to generate slow waves, could be reduced or unstable. As a result, the density of EEG slow waves might be more variable throughout the night, leading to more oscillations between Stages 3 and 4 .

\subsubsection{Oscillations between REM and NREM Sleep}

Pedunculopontine and laterodorsal tegmental cholinergic nuclei are involved in the transitions from non-REM to REM sleep [46]. The noradrenergic neurons of the locus coeruleus are known to have an inhibitory influence on REM sleep [39]. They stabilize non-REM sleep by inhibiting the cholinergic neurons from the pedunculopontine and laterodorsal tegmental $[44,47,48]$. Moreover, increasing noradrenaline levels in the brain using antidepressants can suppress REM sleep [49]. In this context, unstable noradrenergic system could lead to more transition between REM and non-REM sleep.

\subsection{What about the Brain Maturation Delay Hypothesis and Sleep Instability in ADHD?}

The maturation delay hypothesis, or maturational lag model, was proposed in 1973 by Kinsbourne [50]. This model suggests that there is a developmental lag in the central nervous system, which leads to a delayed maturation of cognitive processes in children with ADHD; age-related cognitive performance impairment of ADHD children could correspond to a normal performance at a younger age. The ADHD maturational lag model is largely supported by EEG findings, as well as neuropsychological and neuroanatomical studies $[47,48,51-53]$. Like cognitive maturation, healthy sleep follows a neurodevelopmental process, which can be monitored through EEG. Interestingly, sleep instability found in ADHD seems to fit well into the maturational lag model. The next paragraph will discuss the ontogenetic development of sleep stability for each of the significant unstable oscillations that we found in our sample of ADHD children.

Microarousals are a natural component part of sleep in healthy sleepers [54]. Studies in rodents and humans showed that the number of microarousals decreases during brain maturation $[54,55]$. Thus, the higher number of microarousals that we found in children with ADHD could represent a brain maturational delay. In the same vein, REM/non-REM sleep cycle oscillations are short in infants, and tend to lengthen with brain maturation [41]. Consequently, an increasing number of short transitions between non-REM and REM sleep could also be associated with a brain maturation delay. Finally, oscillations between Stages 3 and 4 are based on the density of EEG slow waves in sleep recording samples. A density of $20 \%$ to $49 \%$ of a sample is considered as Stage 3, while $50 \%$ and more is considered as 
Stage 4 [56]. Healthy brain maturation during childhood is associated with high levels of EEG slow waves until adolescence, where a steady decrease is initiated [57,58]. In this context, a neurodevelopmental delay could lead to lower EEG slow wave density during childhood, and be associated with more oscillations between Stages 3 and 4 .

According to the model, sleep instability in ADHD could be attributable to a maturational brain delay. Thus, sleep disturbances and EEG markers found in ADHD could correspond to the sleep of a younger child, but this hypothesis needs to be tested exhaustively.

\subsection{Strengths and Limitations}

This innovative study is the first to analyze the association between sleep stability and objective attentional performance in children with ADHD, taking sleepiness into consideration. On the one hand, the small number of participants calls for larger confirmatory studies. On the other hand, participants were carefully selected to reduce the probability of type 1 errors. The fact that only boys were studied controlled the variability associated with sex differences in the presentation of ADHD [58]. All of the boys had an ADHD diagnosis without any psychiatric comorbidity nor primary sleep disorders, and psychostimulant medication was withdrawn for $48 \mathrm{~h}$ before entering the study. Another strength is that a habituation night allowed children to get used to the laboratory setting before data was collected. One-to-one matching by age, body mass index, and psychometric measures in two larger groups of participants would improve the generalizability of the present results.

\section{Conclusions}

In recent years, models of sleep and ADHD have included daytime sleepiness as a moderator for the association between sleep disturbances and attentional performance in ADHD. Although we found clinically significant sleep disturbances in ADHD according to parental reports the CSHQ, daytime sleepiness was not significant in this group. Previous studies did not demonstrate an association between sleep instability and daytime sleepiness $[7,8]$. The present study suggests that the association between sleep instability and attentional deficits could reflect an impairment of mechanisms regulating both sleep and vigilance, rather than a consequence of daytime sleepiness. Interestingly, our results are compatible with the maturational lag model of ADHD, and could add a developmental perspective of sleep to this model.

Author Contributions: K.G. contributed to the study conceptualization, methodology, formal analysis, writing — original draft preparation, and writing — review \& editing. M.L. contributed to the study conceptualization, methodology, data collection, formal analysis, and writing - original draft preparation. M.-A.G. contributed to the study conceptualization, methodology, data collection, andwritingreview and editing. R.G. contributed to study conceptualization, formal analysis, methodology, writing—original draft preparation and writing—-review \& editing, supervision, project administration, and funding acquisition. All authors have read and agreed to the published version of the manuscript.

Funding: This research was funded by a grant to R.G. from the Canadian Institutes of Health Research (MOP-79628). K.G. was a recipient of a postdoctoral fellowship from Canadian Institutes of Health Research (415287).

Institutional Review Board Statement: The study was conducted according to the guidelines of the Declaration of Helsinki, and approved by the Institutional Ethics Committee of Hôpital en santé mentale Rivière-des-Prairies (protocol code 03-07).

Informed Consent Statement: Informed consent was obtained from all subjects involved in the study.

Data Availability Statement: The datasets presented in this article are not readily available, as these data are confidential and require an authorization from the Ethical Review Board of the Hôpital Rivière-des-Prairie to be shared. Requests to access the datasets should be directed to comite.ethique.recherche.cnmtl@ssss.gouv.qc.ca. 
Acknowledgments: The authors gratefully thank the support and assistance of Élyse Chevrier for the polysomnographic recordings, scoring, and laboratory coordination. We thank the clinicians and participants for their involvement in this project.

Conflicts of Interest: The authors declare no conflict of interest.

\section{References}

1. American Psychiatric Association. Diagnostic and Statistical Manual of Mental Disorders, 5th ed.; American Psychiatric Publishing: Arlington, VA, USA, 2013.

2. Faraone, S.V.; Biederman, J.; Spencer, T.; Wilens, T.; Seidman, L.J.; Mick, E.; Doyle, A.E. Attention-deficit/hyperactivity disorder in adults: An overview. Biol. Psychiatry 2000, 48, 9-20. [CrossRef]

3. Andrillon, T.; Windt, J.; Silk, T.; Drummond, S.P.A.; Bellgrove, M.A.; Tsuchiya, N. Does the Mind Wander When the Brain Takes a Break? Local Sleep in Wakefulness, Attentional Lapses and Mind-Wandering. Front. Neurosci. 2019, 13, 949. [CrossRef] [PubMed]

4. Diaz-Roman, A.; Hita-Yanez, E.; Buela-Casal, G. Sleep Characteristics in Children with Attention Deficit Hyperactivity Disorder: Systematic Review and Meta-Analyses. J. Clin. Sleep Med. 2016, 12, 747-756. [CrossRef]

5. Corkum, P.; Tannock, R.; Moldofsky, H. Sleep disturbances in children with attention-deficit/hyperactivity disorder. J. Am. Acad. Child Adolesc. Psychiatry 1998, 37, 637-646. [CrossRef]

6. Owens, J.; Gruber, R.; Brown, T.; Corkum, P.; Cortese, S.; O’Brien, L.; Stein, M.; Weiss, M. Future research directions in sleep and ADHD: Report of a consensus working group. J. Atten. Disord. 2013, 17, 550-564. [CrossRef] [PubMed]

7. Miano, S.; Donfrancesco, R.; Bruni, O.; Ferri, R.; Galiffa, S.; Pagani, J.; Montemitro, E.; Kheirandish, L.; Gozal, D.; Pia Villa, M. NREM sleep instability is reduced in children with attention-deficit/hyperactivity disorder. Sleep 2006, $29,797-803$.

8. Akinci, G.; Oztura, I.; Hiz, S.; Akdogan, O.; Karaarslan, D.; Ozek, H.; Akay, A. Sleep Structure in Children With AttentionDeficit/Hyperactivity Disorder. J. Child Neurol. 2015, 30, 1520-1525. [CrossRef]

9. Prihodova, I.; Paclt, I.; Kemlink, D.; Nevsimalova, S. Sleep microstructure is not altered in children with attentiondeficit/hyperactivity disorder (ADHD). Physiol. Res. 2012, 61, 125-133. [CrossRef] [PubMed]

10. Kaufman, A.; Kauffman, N. K-BIT: Kaufman Brief Intelligence Test; Pearson Assesssments: Bloomington, MN, USA, 1990.

11. American Psychiatric Association. Diagnostic and Statistical Manual of Mental Disorders, 4th ed.; text revision; American Psychiatric Publishing: Arlington, VA, USA, 2000.

12. Achenbach, T. Manual for the Child Behavior Checklist/4-18 and 1991 Profile; Department of Psychiatry, University of Vermont: Burlington, VT, USA, 1991.

13. Owens, J.A.; Spirito, A.; McGuinn, M. The children's sleep habits questionnaire (CSHQ): Psychometric properties of a survey instrument for school-aged children. Sleep 2000, 23, 1043-1051. [CrossRef]

14. Rechtschaffen, A.; Kales, A. A Manual of Standardized Terminology, Techniques and Scoring System for Sleep Stages of Humans Subjects; Brain Research Institute, University of California: Los Angeles, CA, USA, 1968.

15. American Academy of Sleep Medicine. The AASM Manual for the Scoring of Sleep and Associated Events Rules, Terminology and Technical Specifications; American Academy of Sleep Medicine: Westchester, IL, USA, 2007.

16. Nomenclature, S.E. American Electroencephalographic Society guidelines for standard electrode position nomenclature. J. Clin. Neurophysiol. 1991, 8, 200-202.

17. Pivik, R.T.; Broughton, R.J.; Coppola, R.; Davidson, R.J.; Fox, N.; Nuwer, M.R. Guidelines for the recording and quantitative analysis of electroencephalographic activity in research contexts. Psychophysiology 1993, 30, 547-558. [CrossRef]

18. Berry, R.B.; Budhiraja, R.; Gottlieb, D.J.; Gozal, D.; Iber, C.; Kapur, V.K.; Marcus, C.L.; Mehra, R.; Parthasarathy, S.; Quan, S.F.; et al. Rules for scoring respiratory events in sleep: Update of the 2007 AASM Manual for the Scoring of Sleep and Associated Events. Deliberations of the Sleep Apnea Definitions Task Force of the American Academy of Sleep Medicine. J. Clin. Sleep Med. 2012, 8 , 597-619. [CrossRef]

19. Conners, C.K. Conners' Continuous Performance Test (CPT-2) Computer Program for Windows, Technical Guide, and Software Manual; Multi Health Systems Inc.: Toronto, ON, USA, 2000.

20. Eiraldi, R.B.; Power, T.J.; Karustis, J.L.; Goldstein, S.G. Assessing ADHD and comorbid disorders in children: The Child Behavior Checklist and the Devereux Scales of Mental Disorders. J. Clin. Child Psychol. 2000, 29, 3-16. [CrossRef]

21. Vaughn, M.L.; Riccio, C.A.; Hynd, G.W.; Hall, J. Diagnosing ADHD (predominantly inattentive and combined type subtypes): Discriminant validity of the behavior assessment system for children and the achenbach parent and teacher rating scales. J. Clin. Child Psychol. 1997, 26, 349-357. [CrossRef]

22. Chen, W.J.; Faraone, S.V.; Biederman, J.; Tsuang, M.T. Diagnostic accuracy of the Child Behavior Checklist scales for attentiondeficit hyperactivity disorder: A receiver-operating characteristic analysis. J. Consult. Clin. Psychol. 1994, 62, 1017-1025. [CrossRef] [PubMed]

23. Rishel, C.W.; Greeno, C.; Marcus, S.C.; Shear, M.K.; Anderson, C. Use of the Child Behavior Checklist as a Diagnostic Screening Tool in Community Mental Health. Res. Soc. Work. Pract. 2005, 15, 195-203. [CrossRef]

24. Lewandowski, A.S.; Toliver-Sokol, M.; Palermo, T.M. Evidence-based review of subjective pediatric sleep measures. J. Pediatr. Psychol. 2011, 36, 780-793. [CrossRef] [PubMed]

25. Miano, S.; Parisi, P.; Villa, M.P. The sleep phenotypes of attention deficit hyperactivity disorder: The role of arousal during sleep and implications for treatment. Med. Hypotheses 2012, 79, 147-153. [CrossRef] 
26. Bruni, O.; Ottaviano, S.; Guidetti, V.; Romoli, M.; Innocenzi, M.; Cortesi, F.; Giannotti, F. The sleep disturbance scale for children (SDSC) Construction and validation of an instrument to evaluate sleep disturbance in childhood and adolescence. J. Sleep Res. 1996, 5, 251-261. [CrossRef]

27. Huber, R.; Ghilardi, M.F.; Massimini, M.; Tononi, G. Local sleep and learning. Nature 2004, 430, 78-81. [CrossRef] [PubMed]

28. Nir, Y.; Staba, R.J.; Andrillon, T.; Vyazovskiy, V.V.; Cirelli, C.; Fried, I.; Tononi, G. Regional slow waves and spindles in human sleep. Neuron 2011, 70, 153-169. [CrossRef] [PubMed]

29. Vyazovskiy, V.V.; Olcese, U.; Hanlon, E.C.; Nir, Y.; Cirelli, C.; Tononi, G. Local sleep in awake rats. Nature 2011, $472,443-447$. [CrossRef] [PubMed]

30. Hung, C.S.; Sarasso, S.; Ferrarelli, F.; Riedner, B.; Ghilardi, M.F.; Cirelli, C.; Tononi, G. Local experience-dependent changes in the wake EEG after prolonged wakefulness. Sleep 2013, 36, 59-72. [CrossRef] [PubMed]

31. Bernardi, G.; Betta, M.; Ricciardi, E.; Pietrini, P.; Tononi, G.; Siclari, F. Regional Delta Waves In Human Rapid Eye Movement Sleep. J. Neurosci. 2019, 39, 2686-2697. [CrossRef] [PubMed]

32. Quercia, A.; Zappasodi, F.; Committeri, G.; Ferrara, M. Local Use-Dependent Sleep in Wakefulness Links Performance Errors to Learning. Front. Hum. Neurosci. 2018, 12, 122. [CrossRef]

33. Funk, C.M.; Honjoh, S.; Rodriguez, A.V.; Cirelli, C.; Tononi, G. Local Slow Waves in Superficial Layers of Primary Cortical Areas during REM Sleep. Curr. Biol. 2016, 26, 396-403. [CrossRef]

34. Bernardi, G.; Siclari, F.; Yu, X.; Zennig, C.; Bellesi, M.; Ricciardi, E.; Cirelli, C.; Ghilardi, M.F.; Pietrini, P.; Tononi, G. Neural and behavioral correlates of extended training during sleep deprivation in humans: Evidence for local, task-specific effects. J. Neurosci. 2015, 35, 4487-4500. [CrossRef]

35. Geissler, J.; Romanos, M.; Hegerl, U.; Hensch, T. Hyperactivity and sensation seeking as autoregulatory attempts to stabilize brain arousal in ADHD and mania? Atten. Defic. Hyperact. Disord. 2014, 6, 159-173. [CrossRef]

36. Chamberlain, S.R.; Robbins, T.W. Noradrenergic modulation of cognition: Therapeutic implications. J. Psychopharmacol. 2013, 27, 694-718. [CrossRef]

37. Borodovitsyna, O.; Flamini, M.; Chandler, D. Noradrenergic Modulation of Cognition in Health and Disease. Neural. Plast. 2017, 2017, 6031478. [CrossRef]

38. Engert, V.; Pruessner, J.C. Dopaminergic and noradrenergic contributions to functionality in ADHD: The role of methylphenidate. Curr. Neuropharmacol. 2008, 6, 322-328. [CrossRef]

39. Jones, B.E. Arousal and sleep circuits. Neuropsychopharmacology 2020, 45, 6-20. [CrossRef] [PubMed]

40. Dos Santos Lima, G.Z.; Lobao-Soares, B.; Corso, G.; Belchior, H.; Lopes, S.R.; de Lima Prado, T.; Nascimento, G.; Franca, A.C.; Fontenele-Araujo, J.; Ivanov, P.C. Hippocampal and cortical communication around micro-arousals in slow-wave sleep. Sci. Rep. 2019, 9, 5876. [CrossRef] [PubMed]

41. Scammell, T.E.; Arrigoni, E.; Lipton, J.O. Neural Circuitry of Wakefulness and Sleep. Neuron 2017, 93, 747-765. [CrossRef]

42. Samuels, E.R.; Szabadi, E. Functional neuroanatomy of the noradrenergic locus coeruleus: Its roles in the regulation of arousal and autonomic function part II: Physiological and pharmacological manipulations and pathological alterations of locus coeruleus activity in humans. Curr. Neuropharmacol. 2008, 6, 254-285. [CrossRef] [PubMed]

43. Saboory, E.; Ghasemi, M.; Mehranfard, N. Norepinephrine, neurodevelopment and behavior. Neurochem. Int. 2020, 135, 104706. [CrossRef]

44. Dang-Vu, T.T.; Schabus, M.; Desseilles, M.; Albouy, G.; Boly, M.; Darsaud, A.; Gais, S.; Rauchs, G.; Sterpenich, V.; Vandewalle, G.; et al. Spontaneous neural activity during human slow wave sleep. Proc. Natl. Acad. Sci. USA 2008, 105, 15160-15165. [CrossRef]

45. Eschenko, O.; Magri, C.; Panzeri, S.; Sara, S.J. Noradrenergic neurons of the locus coeruleus are phase locked to cortical up-down states during sleep. Cereb. Cortex 2012, 22, 426-435. [CrossRef]

46. Van Dort, C.J.; Zachs, D.P.; Kenny, J.D.; Zheng, S.; Goldblum, R.R.; Gelwan, N.A.; Ramos, D.M.; Nolan, M.A.; Wang, K.; Weng, F.J.; et al. Optogenetic activation of cholinergic neurons in the PPT or LDT induces REM sleep. Proc. Natl. Acad. Sci. USA 2015, 112, 584-589. [CrossRef]

47. Arns, M.; Conners, C.K.; Kraemer, H.C. A decade of EEG Theta/Beta Ratio Research in ADHD: A meta-analysis. J. Atten. Disord. 2013, 17, 374-383. [CrossRef]

48. Johnstone, S.J.; Barry, R.J.; Clarke, A.R. Ten years on: A follow-up review of ERP research in attention-deficit/hyperactivity disorder. Clin. Neurophysiol. 2013, 124, 644-657. [CrossRef] [PubMed]

49. Williams, J.A.; Reiner, P.B. Noradrenaline hyperpolarizes identified rat mesopontine cholinergic neurons in vitro. J. Neurosci. 1993, 13, 3878-3883. [CrossRef] [PubMed]

50. Kinsbourne, M. The control of attention by interaction between the hemispheres. In Attention and Performance; Kornblun, S., Ed.; Academic Press: New York, NY, USA, 1973; Volume IV, pp. 239-256.

51. Rubia, K. Neuro-anatomic evidence for the maturational delay hypothesis of ADHD. Proc. Natl. Acad. Sci. USA 2007, 104, 19663-19664. [CrossRef] [PubMed]

52. Shaw, P.; Eckstrand, K.; Sharp, W.; Blumenthal, J.; Lerch, J.P.; Greenstein, D.; Clasen, L.; Evans, A.; Giedd, J.; Rapoport, J.L. Attention-deficit/hyperactivity disorder is characterized by a delay in cortical maturation. Proc. Natl. Acad. Sci. USA 2007, 104, 19649-19654. [CrossRef] [PubMed]

53. Shaw, P.; Malek, M.; Watson, B.; Sharp, W.; Evans, A.; Greenstein, D. Development of cortical surface area and gyrification in attention-deficit/hyperactivity disorder. Biol. Psychiatry 2012, 72, 191-197. [CrossRef] 
54. Gradwohl, G.; Olini, N.; Huber, R. Sleep/wake movement velocities, trajectories and micro-arousals during maturation in rats. BMC Neurosci. 2017, 18, 24. [CrossRef]

55. Scher, M.S.; Johnson, M.W.; Ludington, S.M.; Loparo, K. Physiologic brain dysmaturity in late preterm infants. Pediatr. Res. 2011, 70, 524-528. [CrossRef]

56. Markov, D.; Goldman, M. Normal sleep and circadian rhythms: Neurobiologic mechanisms underlying sleep and wakefulness. Psychiatr. Clin. N. Am. 2006, 29, 841-853. [CrossRef]

57. Feinberg, I.; Higgins, L.M.; Khaw, W.Y.; Campbell, I.G. The adolescent decline of NREM delta, an indicator of brain maturation, is linked to age and sex but not to pubertal stage. Am. J. Physiol. Regul. Integr. Comp. Physiol. 2006, 291, R1724-R1729. [CrossRef]

58. Kurth, S.; Jenni, O.G.; Riedner, B.A.; Tononi, G.; Carskadon, M.A.; Huber, R. Characteristics of sleep slow waves in children and adolescents. Sleep 2010, 33, 475-480. [CrossRef] 